\title{
Redução do imposto sobre produtos industrializados e seu efeito sobre a venda de automóveis no Brasil: uma análise do período de 2006 a 2013
}

Tax reduction on industrialized products and its effect on car sales in Brazil: an analysis of the period 2006 to 2013

\section{Reducción del impuesto sobre productos industrializados y su efecto sobre la venta de automóviles en Brasil: un análisis del período de 2006 a 2013}

Marcelo Driemeyer Wilbert

Doutor em Economia pela Universidade de Brasília - UnB

Professor do Departamento de Ciências Contábeis e Atuariais (CCA), Faculdade de Economia,

Administração e Contabilidade (FACE), Universidade de Brasília (UNB)

Endereço: Campus Universitário Darcy Ribeiro, Prédio da FACE, Asa Norte

CEP: 70.910-900 - Brasília/ DF - Brasil

E-mail:marcelodw@unb.br

Telefone: +55 (61) 3107-0795

André Luiz Marques Serrano

Doutor em Economia pela Universidade de Brasília - UnB

Professor do Departamento Administração, Faculdade de Economia, Administração e Contabilidade

(FACE), Universidade de Brasília (UNB)

Endereço: Campus Universitário Darcy Ribeiro, Prédio da FACE, Asa Norte

CEP: 70.910-900 - Brasília/ DF - Brasil

E-mail: andrelms@unb.br

Telefone: +55 (61) 3107-7110

Rodrigo de Souza Gonçalves

Doutor em Ciências Contábeis pela Universidade de Brasília - UnB

Professor do Departamento de Ciências Contábeis e Atuariais (CCA), Faculdade de Economia,

Administração e Contabilidade (FACE), Universidade de Brasília (UNB)

Endereço: Campus Universitário Darcy Ribeiro, Prédio da FACE, Asa Norte

CEP: 70.910-900 - Brasília/ DF - Brasil

E-mail: rgoncalves@unb.br

Telefone: +55 (61) 3107-0798

Laís Sienna Alves

Graduada em Ciências Contábeis pela Universidade de Brasília

Departamento de Ciências Contábeis e Atuariais (CCA), Faculdade de Economia, Administração e

Contabilidade (FACE), Universidade de Brasília (UNB)

Endereço: Campus Universitário Darcy Ribeiro, Prédio da FACE, Asa Norte

CEP: 70.910-900 - Brasília/ DF - Brasil

E-mail: lais_sienna@hotmail.com

Artigo recebido em 10/02/2014. Revisado por pares em 17/09/2014. Reformulado em 16/10/2014. Recomendado para publicação em 15/11/2014 por Sandra Rolim Ensslin (Editora Científica). Publicado em 15/12/2014. 


\title{
Resumo
}

No período entre 2006 a 2013 a alíquota do Imposto sobre Produtos Industrializados (IPI) para automóveis foi reduzida em dois momentos, com o objetivo de aumentar a demanda destes e estimular a economia. Assim, o objetivo deste artigo é verificar se a redução da alíquota do IPI causou alterações nas vendas de automóveis. Por meio de análise de regressão, foi testada a influência da redução da alíquota do IPI sobre a venda de automóveis. Os resultados obtidos demostraram que não é possível afirmar que a redução da alíquota do IPI foi capaz de modificar o comportamento da venda de automóveis. Como resultados adicionais, observa-se no período a expansão do crédito à pessoa física, mesmo em uma situação de declínio da renda real do trabalhador. Outra observação foi de que o preço do automóvel popular teve um aumento abaixo da inflação, indicando uma mudança de preços relativos.

Palavras-chaves: Imposto sobre produtos industrializados. IPI. Venda de automóveis. Renúncia fiscal.

\begin{abstract}
In the period between 2006 and 2013 the tax rate on industrialized products for cars was reduced in two stages, with the aim of increasing their demand and stimulate the economy. Thus, the aim of this paper is to verify whether the reduction in the rate of tax on industrialized products caused alterations in auto sales. Through regression analysis, was tested the influence of the reduction in of tax on industrialized products on the cars sale. The results showed that it is not possible to state that the reduction in tax on industrialized products rate was able to change the behavior of car sales. As additional results, can be seen in the period the expansion of credit to the natural person, even in a situation of worker's real income declining. Another observation was that the price of the economy car had an increase below inflation, indicating a change in relative prices.
\end{abstract}

Keywords: Tax on industrialized products. TIP. Car sales. Fiscal waiver.

\section{Resumen}

En el período entre 2006 y 2013 la alícuota del Impuesto sobre Productos Industrializados para automóviles fue reducida en dos momentos, con el objetivo de aumentar la demanda de estos y estimular la economía. Así, el objetivo de este artículo es verificar si la reducción de la alícuota del IPI causó alteraciones en las ventas de automóviles. Por medio del análisis de regresión, fue probada la influencia de la reducción de la alícuota del IPI sobre la venta de automóviles. Los resultados obtenidos demostraron que no es posible afirmar que la reducción de la alícuota del IPI fue capaz de modificar el comportamiento de la venta de automóviles. Como resultados adicionales, se observa en el período la expansión del crédito a la persona física, aun en una situación de declive de la renta real del trabajador. Otra observación fue que el precio del automóvil popular tuvo un aumento abajo de la inflación, indicando un cambio de precios relativos.

Palabras clave: Impuesto sobre productos industrializados. IPI. Venta de automóviles. Renuncia fiscal. 


\section{Introdução}

A indústria automobilística tem um papel importante nas cadeias produtivas. Segundo Casotti e Goldenstein (2008), estima-se que 50\% do total da borracha, $25 \%$ do total de vidro e $15 \%$ do total de aço produzidos no mundo se destinem à indústria automobilística. Scavarda e Hamacher (2001) discutem o papel da indústria automobilística brasileira na cadeia de suprimentos.

Dada a propagação da crise financeira mundial a partir de julho de 2008 (FREITAS, 2009), no período de 2008 a 2013 o Governo Federal adotou duas vezes a redução da alíquota do Imposto sobre Produtos Industrializados (IPI) com o objetivo de estimular ou manter as vendas de automóveis.

Merece destaque o estudo realizado por Alvarenga et al. (2010), no qual demonstra que a redução da alíquota do IPI foi uma das medidas adotadas no Brasil para combater os efeitos da crise financeira mundial que começou no final de 2008. A primeira redução da alíquota ocorreu entre o final de 2008 e o início de 2010. A segunda redução do IPI começou no início de 2012 e encerrou no final de 2013.

Assim, dado o esforço de renúncia fiscal por parte da União, fica o questionamento quanto à efetividade da política de redução da alíquota do IPI. Portanto, este estudo tem por objetivo verificar se a redução do IPI causou alterações nas vendas de automóveis.

Por meio de análise de estatística descritiva e da técnica de regressão linear múltipla, procura-se investigar a quantidade de automóveis vendidos e a relação desta variável com redução da alíquota do IPI. Além disso, também são investigados a arrecadação tributária com o IPI, a renda média do trabalhador assalariado, o crédito à pessoa física e o preço do automóvel popular.

Esta pesquisa justifica-se em razão de discutir a efetividade de uma política de estímulo setorial, com a renúncia de arrecadação tributária. Nesse sentido, é esperado que medidas que favoreçam setores específicos, no caso, o setor automotivo, tenha uma repercussão social superior aos benefícios que a arrecadação renunciada poderia gerar, ponderado pela eventual queda de vendas do setor e de seus efeitos negativos.

Com esse propósito, o artigo está organizado da seguinte forma. A segunda seção explora a revisão teórica, em que foram feitas algumas considerações acerca do IPI, explanando sobre o surgimento, a legislação, os princípios e as alíquotas. Aborda-se também a desoneração do imposto e a crise financeira mundial e as contribuições de outros estudos sobre a recente redução do IPI. A terceira seção é destinada a explicar a metodologia usada e a seção quatro apresenta a análise dos dados. Por fim, a quinta seção engloba as conclusões oriundas desse estudo e apontamentos para uma agenda futura de novas pesquisas acerca do tema.

\section{Revisão Teórica}

\subsection{Imposto Sobre Produtos Industrializados}

O estudo feito por Xavier (2008) apresenta um breve histórico do Imposto sobre Produtos Industrializados, que teve origem no antigo Imposto sobre Consumo com a 
Constituição de 1934. Já na Constituição de 1946, foi atribuída à União a criação do Imposto sobre Consumo de Mercadorias, e também a instituição do Imposto sobre Produção.

Ainda segundo Xavier (2008), foi apenas com a Emenda Constitucional $\mathrm{N}^{\mathrm{o}} 18$, de primeiro de dezembro de 1965, que o Imposto sobre Produtos Industrializados (IPI) surgiu pela primeira vez, e foi atribuído a ele o caráter não cumulativo e a seletividade em função da essencialidade dos produtos. Desta forma, o IPI é considerado um imposto seletivo, pois suas alíquotas variam conforme a necessidade do produto, quanto maior a sua essencialidade, menor irá ser a alíquota, e da mesma forma, quanto menor a necessidade do produto, quanto mais supérfluo ele for, maior será a alíquota do IPI.

Com a promulgação da Constituição Federal (CF) de 1988 foi mantida a competência da União para instituir, entre outros, o Imposto sobre Produtos Industrializados, e também foi mantida a seletividade dos produtos e a não-cumulatividade. Além disso, o IPI está disposto no Código Tributário Nacional, artigos 46 a 51, que define o fato gerador, a base de cálculo e os contribuintes.

O Decreto $\mathrm{N}^{\circ}$ 4.544, de dezembro de 2002 estabelecia a regulamentação, a fiscalização, a arrecadação e administração do IPI e sua tabela com as alíquotas e a classificação dos produtos prevista no Decreto $N^{0}$ 6006/06, mas em decorrência da crise financeira e em virtude da desoneração do imposto o Presidente da República editou a Medida Provisória $\mathrm{N}^{\circ} 451 / 08$, reduzindo as alíquotas dos automóveis. Após o prazo legal de vigência da MP, o governo publicou o Decreto $\mathrm{N}^{\circ} 6.809 / 09$ prorrogando a redução das alíquotas. A partir de então, foram feitas várias alterações na legislação desse imposto e hoje suas disposições estão no Decreto $\mathrm{N}^{\mathrm{o}} 7.212 / 10$.

Embora o IPI possua função extrafiscal, já que é seletivo em razão da essencialidade do produto (art.153 da Constituição Federal), isto é, não possui somente a finalidade arrecadatória, ou seja, o governo pode tanto incentivar a comercialização de determinados produtos como pode desestimular a compra de outros. De acordo com Xavier (2008), o IPI tem grande relevância no orçamento da União, dos Estados, do Distrito Federal e dos Municípios, no qual afirma que a principal função do imposto não é a financeira, de arrecadar dinheiro para o Governo, mas sim de incentivar determinados setores da economia por meio de alíquotas menores, ou até mesmo alíquota zero para alguns produtos.

O princípio da essencialidade está na CF no art. $153, \S 3^{\circ}$, I, no qual descreve que o IPI será seletivo, em função da essencialidade do produto. De acordo com Ferreira (2009), essencial é algo que é de extrema importância e não pode faltar, dado que é imprescindível. Portanto, a seletividade, nesse caso, é ter alíquotas diferenciadas de acordo com o produto ou do tipo de produto e o critério dessa seletividade é o grau de essencialidade do produto.

Assim, a alíquota do imposto varia conforme o produto e normalmente possui maior incidência sobre produtos considerados supérfluos, como bebidas, cigarros, perfumes, automóveis e alíquotas mais baixas para produtos de primeira necessidade ou essenciais, como alimentícios, vestuário e calçados.

O princípio da não-cumulatividade também está prevista na Constituição Federal e é tratado no artigo 49 do Código Tributário Nacional. Um imposto não cumulativo é o que não pode ser cobrado em cascata, que não pode incidir sobre o valor do próprio imposto. Apenas dois impostos tem esse princípio previsto pela Constituição Federal, o IPI e o Imposto sobre Circulação de Mercadorias e Serviços (ICMS). O objetivo é impedir que as incidências sucessivas nas diversas operações da cadeia econômica de um produto impliquem em um ônus tributário muito alto, derivado da múltipla tributação da mesma base econômica. Então, 
no instante de se apurar o IPI, sobre o valor incidente da saída do produto, deve ser subtraído o valor do IPI incidente na entrada.

As alíquotas do IPI estão dispostas na Tabela de Incidência do Imposto sobre Produtos Industrializados (TIPI), com percentuais que variam de $0 \%$ até $330 \%$, sendo que este maior é aplicado sobre os cigarros. A mercadoria pode ser enquadrada na tabela de acordo com quatro possibilidades: ou o produto é isento, ou é imune, ou tem alíquota zero, ou tem alíquota positiva. A TIPI mais recente foi aprovada pelo Decreto $\mathrm{N}^{0} 7.660 / 2011$ e a última alteração, até agora, foi feita pelo Decreto $N^{\circ} 8116$, de 30 de setembro de 2013.

\subsection{Desoneração do IPI e a Crise Financeira Mundial}

A crise financeira mundial que começou em 2008 nos Estados Unidos da América (EUA), de acordo com Freitas (2009), teve como estopim a crise imobiliária, ou seja, em uma crise no pagamento de hipotecas que se alastrou pela economia e contaminou o sistema mundial. Nessa perspectiva, a crise no Brasil não afetou diretamente os bancos, conforme Franzoi (2010), que não possuíam títulos ligados às hipotecas, mas atingiu vários setores por causa da forte contração de crédito e consumo mundial. Sendo assim, para combater os efeitos da crise econômica no Brasil, o Governo passou a atuar com mais intensidade na condução e formulação da economia do país.

Alvarenga et al. (2010) argumentam que a redução da alíquota do IPI para os automóveis foi uma das medidas adotadas para evitar a tendência de recessão provocada pela crise mundial. Além da indústria automobilística, os produtos da linha branca também foram contemplados com a redução da alíquota do IPI. A intenção com a desoneração do IPI era de aumentar o consumo dos produtos do mercado interno para preservar o equilíbrio econômico e evitar uma recessão.

A primeira redução do IPI teve a duração de mais de um ano e foi feita por meio de uma Medida Provisória (MP), a No 451/08. Começando em dezembro de 2008, tinha previsão para acabar em março de 2009, mas foi prorrogada algumas vezes durante esse ano e permaneceu até 31 de março de 2010.

A definição dos percentuais das alíquotas estava relacionada à potência do motor, ao tipo de combustível e ao local de produção, ou seja, se veículo nacional ou importado. De dezembro de 2008 a setembro de 2009 os carros populares, de até mil cilindradas (1.0), tiveram o IPI reduzido de 7\% para zero. Os carros com cilindradas entre mil e duas mil e movidos à gasolina foram reduzidos de $13 \%$ para $6,5 \%$, para os biocombustíveis (álcool e gasolina) a alíquota caiu de $11 \%$ para $5,5 \%$. Contudo, não houve alteração para veículos com mais de duas mil cilindradas. Estas alterações podem ser observadas nos Quadro 1 e 2.

A partir de outubro de 2009 as alíquotas foram subindo gradativamente, mantendo um maior incentivo para carros bicombustíveis, e em $1^{\text {o }}$ de abril de 2010 o IPI voltou a ser cobrado integralmente.

Contudo, diante do agravamento da crise financeira no mundo, a alíquota dos produtos industrializados foi reduzida pela segunda vez, em maio de 2012. Conforme Mantega (2012), esta segunda redução das alíquotas tinha por objetivo combater as consequências dos problemas causados pela crise. O benefício deveria ter cessado no final de agosto do mesmo ano, mas foi prorrogado por diversas vezes e tem previsão para encerrar-se ao final de dezembro de 2014. 
Nesta segunda redução, também, as alíquotas foram relacionadas com a potência do motor, o tipo de combustível e o local de produção. As alíquotas não foram iguais durante todo do período desta segunda redução.

Quadro 1 - Alíquota do IPI Antes e Depois da Redução - Veículos Nacionais

\begin{tabular}{|c|c|c|c|}
\hline \multirow{2}{*}{ Mês/Ano } & Cilindradas & $\begin{array}{c}\text { Antes da } \\
\text { Redução }\end{array}$ & $\begin{array}{c}\text { Depois da } \\
\text { Redução }\end{array}$ \\
\hline \multirow{4}{*}{$\begin{array}{c}\text { Dezembro de 2008 a } \\
\text { Setembro de 2009 }\end{array}$} & Até mil (1.0) & $7 \%$ & $0 \%$ \\
\cline { 2 - 4 } & $\begin{array}{c}\text { De mil (1.0) a duas mil (2.0) álcool e } \\
\text { biocombustivel }\end{array}$ & $11 \%$ & $5,5 \%$ \\
\cline { 2 - 4 } & De mil (1.) a duas mil (2.0) gasolina & $13 \%$ & $6,5 \%$ \\
\cline { 2 - 4 } & Veículos utilitários & $4 \%$ & $1 \%$ \\
\hline \multirow{4}{*}{ Maio a Dezembro de 2012 } & Até mil (1.0) & $7 \%$ & $0 \%$ \\
\cline { 2 - 4 } & De mil (1.0) a duas mil (2.0) álcool e \\
biocombustível & $11 \%$ & $5,5 \%$ \\
\cline { 2 - 4 } & De mil (1.) a duas mil (2.0) gasolina & $13 \%$ & $6,5 \%$ \\
\cline { 2 - 4 } & Veículos utilitários & $4 \%$ & $1 \%$ \\
\cline { 2 - 4 } & Até mil (1.0) & $7 \%$ & $7 \%$ \\
\hline \multirow{5}{*}{2013} & De mil (1.0) a duas mil (2.0) álcool e \\
biocombustível & $11 \%$ & $8 \%$ \\
\cline { 2 - 4 } & De mil (1.) a duas mil (2.0) gasolina & $13 \%$ & $2 \%$ \\
\cline { 2 - 4 } & Veículos utilitários & $4 \%$ & $7 \%$ \\
\hline
\end{tabular}

Fonte: Elaborado pelos autores.

De maio ao final de 2012 a alíquota para carros de até mil cilindradas foi nula, para veículos de mil cilindradas a duas mil cilindradas a alíquota foi de 5,5\% para álcool e biocombustíveis e de 6,5\% para carros a gasolina, todos de produção nacional. Para os veículos utilitários a alíquota foi de 1\% neste período (Quadro 1).

Para o ano de 2013 os percentuais subiram, mas ainda continuaram abaixo das alíquotas praticadas antes de 2008. Os carros de até mil cilindradas estavam com a alíquota de $2 \%$, os de mil até duas mil cilindradas a álcool e biocombustíveis com $7 \%$ e os movidos à gasolina com $8 \%$. Os veículos utilitários tinham a alíquota igual a $2 \%$. Já os caminhões, que desde dezembro de 2008 tem isenção do imposto, continuam com o IPI zero até o final do ano (Quadro 1).

Os carros importados, a partir de 16 de dezembro de 2011, tiveram suas alíquotas aumentadas em 30 pontos percentuais e, assim, ficou estabelecido que os veículos que não têm $65 \%$ de autopeças fabricadas no Brasil, Mercosul e México pagam IPI maior. Para modelos de mil cilindradas, a alíquota passou de $7 \%$ para $37 \%$. Modelos de até duas mil cilindradas tiveram a taxa ampliada de $11 \%$ para $41 \%$ (versões biocombustível) e de $13 \%$ para $43 \%$ (gasolina). O imposto para os carros com motor acima de duas mil cilindradas saltou de $25 \%$ para $55 \%$.

Com a decisão do governo, em maio, de reduzir o IPI para ampliar as vendas, principalmente das montadoras que estavam com pátios lotados, a alíquota para os importados caiu de $37 \%$ para $30 \%$ (modelos de mil cilindradas) e de $41 \%$ para $35,5 \%$ e de $43 \%$ para $36,5 \%$ (modelos até duas mil cilindradas biocombustível e a gasolina, respectivamente), conforme o Quadro 2. 
Redução do imposto sobre produtos industrializados e seu efeito sobre a venda de automóveis no Brasil:...

Quadro 2 - Alíquota do IPI Antes e Depois da Redução - Veículos Importados

\begin{tabular}{|c|c|c|c|}
\hline \multirow{2}{*}{ Mês/Ano } & Cilindradas & $\begin{array}{c}\text { Antes da } \\
\text { Redução }\end{array}$ & $\begin{array}{c}\text { Depois da } \\
\text { Redução }\end{array}$ \\
\hline \multirow{3}{*}{$\begin{array}{c}\text { Dezembro de 2008 a } \\
\text { Setembro de 2009 }\end{array}$} & Até mil (1.0) & $7 \%$ & - \\
\cline { 2 - 4 } & $\begin{array}{c}\text { De mil (1.0) a duas mil (2.0) álcool e } \\
\text { biocombustível }\end{array}$ & $11 \%$ & - \\
\cline { 2 - 4 } & De mil (1.) a duas mil (2.0) gasolina & $13 \%$ & - \\
\hline \multirow{4}{*}{ Maio a Dezembro de 2012 } & Até mil (1.0) & $37 \%$ & $30 \%$ \\
\cline { 2 - 4 } & $\begin{array}{c}\text { De mil (1.0) a duas mil (2.0) álcool e } \\
\text { biocombustível }\end{array}$ & $41 \%$ & $35,5 \%$ \\
\cline { 2 - 4 } & De mil (1.) a duas mil (2.0) gasolina & $43 \%$ & $36,5 \%$ \\
\cline { 2 - 4 } & Até mil (1.0) & $37 \%$ & $32 \%$ \\
\hline \multirow{2}{*}{2013} & De mil (1.0) a duas mil (2.0) álcool e \\
biocombustível & $41 \%$ & $37 \%$ \\
\cline { 2 - 4 } & De mil (1.) a duas mil (2.0) gasolina & $43 \%$ & $38 \%$ \\
\hline
\end{tabular}

Fonte: Elaborado pelos autores.

Os automóveis importados até o final de 2013 têm seus percentuais fixados em 32\% para motores 1.0, os de mil até duas mil cilindradas biocombustível é de $37 \%$ e para os que usam gasolina é de 38\%. Os de motorização 2.0 ou mais, biocombustíveis é de $48 \%$, e gasolina 55\% (Quadro 2).

\subsection{Outros Estudos sobre s Redução do IPI Automóveis}

A redução do IPI, com relação à venda de automóveis, provocou um interesse tanto da sociedade como um interesse no meio acadêmico. Há muitas críticas a essa política por parte da população, por não saber ao certo se essa medida foi eficaz e há também alguns trabalhos acadêmicos que fizeram uma análise dos efeitos da redução do imposto.

Alvarenga et al. (2010) analisou o impacto da redução do IPI sobre as vendas de veículos no período de janeiro a novembro de 2009. O texto faz um detalhamento da história da indústria automobilística no Brasil, pois era um setor que vinha crescendo na economia antes do agravamento da crise financeira. Foi utilizado um teste econométrico de cointegração e assumiu-se que as vendas são uma função do preço, da renda e do crédito para a aquisição de veículos. Os resultados do estudos apontam que a redução do IPI foi, importante para a recuperação das vendas e foi responsável por $20,7 \%$ das vendas no período analisado, mas que a concessão de crédito para a compra de veículos não pode ser desprezada.

Franzoi (2010), estudando o impacto da redução do IPI dos veículos automotores, em virtude da crise financeira, concluiu, por meio de uma análise exploratória de dados relacionados à venda de veículos e a arrecadação do IPI, que as vendas de veículos novos no ano de 2009 sofreu um aumento de $11,35 \%$ em relação ao ano de 2008 , enquanto houve uma redução da arrecadação do IPI, mas que não afetou diretamente a arrecadação de tributos federal no ano de 2009. A autora argumenta que a desoneração do imposto foi importante para que as pessoas comprassem mais esse tipo de bem e que combateu a ameaça de desemprego na indústria automotiva nacional.

Os dois trabalhos, por meio de métodos diferentes, destacam que a política pública de redução do IPI foi importante para que a venda de automóveis não fosse prejudicada no período em que a crise mundial afetava tantos países, tendo um efeito positivo como previsto. 


\section{Metodologia}

Considerando que o objetivo deste artigo é verificar se a redução da alíquota do IPI causou alterações nas vendas de automóveis, investigou-se um conjunto de dados para o período de janeiro de 2006 a agosto de 2013, por meio de estatística descritiva e a análise de regressão múltipla. Foram estudados os seguintes dados: arrecadação do IPI, vendas de automóveis, renda média do trabalhador assalariado, saldo de crédito para pessoas físicas e preço de automóvel básico, cuja justificativa para a escolha de tais variáveis encontra-se mais adiante. Observa-se Alvarenga et al. (2010) também utilizaram variáveis de renda e de crédito para avaliar o impacto da redução do IPI na venda de automóveis.

Em um primeiro momento foi utilizada a estatística descritiva para que fosse possível observar o comportamento dos dados coletados, que foram à venda dos veículos no varejo nacional, a arrecadação de IPI total e IPI automóveis no período, a arrecadação de receitas no ano de 2012, a renda média do trabalhador assalariado e o preço médio do veículo popular.

Nesse contexto, o IPI total, o IPI automóveis, o crédito e a renda média do trabalhador assalariado foram deflacionados utilizando o Índice Nacional de Preços ao Consumidor Amplo (IPCA), para que a análise não fosse enviesada pela inflação do período. Optou-se deflacionar esses dados pelo IPCA, porque é um índice que abrange famílias com rendimentos mensais entre um e quarenta salários mínimos e que mede a inflação dos principais produtos e serviços utilizados pela população. Observa-se que os dados referentes à renda mensal do trabalhador assalariado representam a média dos rendimentos das pessoas ocupadas na regiões metropolitanas de Porto Alegre, Rio de Janeiro, São Paulo, Salvador, Recife e Belo Horizonte.

O preço médio do carro popular teve como base o veículo Gol City (Trend) 1.0, total flex, 8 válvulas, 4 portas. Foi utilizado esse automóvel, porque o VW Gol foi o carro mais vendido no período analisado de acordo com a Fenabrave (2013). O preço médio do veículo está em valores nominais para que possa ser analisada a variação dos preços. Para esse preço médio foi elaborado um índice denominado IG (Índice Gol). O IG foi elaborado para comparar a variação percentual do preço médio do carro popular com a variação percentual do IPCA, ambos tendo como base o mês de janeiro de 2006.

A variável relativa à venda de automóveis (VA) é referente à venda de automóveis ocorrida de janeiro de 2006 até agosto de 2013. Foram empregadas duas variáveis controle. A renda média do trabalhador assalariado foi escolhida como variável, porque reflete a capacidade do poder de compra das pessoas ocupadas com o passar do tempo. Deseja-se com esta variável controlar o efeito da renda sobre o consumo de automóveis.

Outra variável controle, o crédito disponível para pessoas físicas, foi utilizada a fim de controlar o efeito do crédito. Isto é, para uma maior disponibilidade de crédito, as pessoas podem comprar mais e assim podem contribuir, também, para o crescimento das vendas de veículos.

Para a existência ou não da redução do IPI foi empregada uma variável dummy, chamada de IPI. Adotou-se o valor zero para esta variável para os meses sem a redução da alíquota e valor um para os meses com redução. A hipótese é que com a redução do IPI as vendas de automóveis aumentaram. 
Nessa análise não foi possível usar uma variável preço médio de veículos, pois os valores encontrados foram de automóveis que já continham a redução do IPI e isso poderia influenciar na análise.

Para tanto, os estimadores dos coeficientes da equação foram calculados pelos Métodos dos Mínimos Quadrados Ordinários (MQO). Este método é usado para estimar o modelo de regressão linear clássico. Segundo o teorema de Gauss Markov, os parâmetros do MQO são os melhores estimadores lineares não viesados, isto é, o valor esperado de cada estimador é igual ao parâmetro que se deseja estimar, sendo que os estimadores de MQO ainda podem ser os mais eficientes segundo Gujarati (2000). A partir das informações citadas, foi estimado o modelo de regressão linear múltipla que descreve o relacionamento entre a variável dependente e as variáveis independentes. O modelo utilizado é expresso na equação (1):

$$
V A_{t}=\beta_{0}+\beta_{1} I P I_{t}+\beta_{2} T+\beta_{3} I P I_{t} T_{t}+\beta_{4} \operatorname{Rend}_{t}+\beta_{5} \operatorname{Cred}_{t}+u_{t}
$$

No Quadro 3 são apresentadas as variáveis da equação 1, o sinal esperado dos coeficientes tanto para a regressão 1 (janeiro de 2006 até março de 2010) quanto à regressão 2 (abril de 2010 até agosto de 2013), estimados pelo MQO, além das descrições das variáveis e as fontes dos dados. Na equação 1 definiu-se como variável dependente a venda de automóveis $(V A)$ e como variáveis explicativas a renda média do trabalhador assalariado (Rend), o crédito para pessoa física (Cred), a existência ou não do IPI no período analisado $(I P I)$ e uma variável tendência $(T)$.

Quadro 3 - Variáveis na estimação da Equação 1 pelo MQO

\begin{tabular}{|c|c|c|c|c|}
\hline Variáveis & Regressão 1 & Regressão 2 & Descrição & Fonte dos Dados \\
\hline $\boldsymbol{V} \boldsymbol{A}_{t}$ & & & Venda de automóveis no período $t$ & $\begin{array}{c}\text { Federação Nacional de } \\
\text { Veículos Automotores } \\
\text { (Fenabrave). }\end{array}$ \\
\hline$I P I_{t}$ & + & + & $\begin{array}{l}\text { Variável qualitativa igual a } 1 \text { se houve } \\
\text { redução do IPI e a } 0 \text { caso contrário. }\end{array}$ & Receita Federal do Brasil. \\
\hline$T$ & + & + & Variável tendência temporal. & - \\
\hline $\operatorname{Rend}_{t}$ & + & + & $\begin{array}{l}\text { Renda média do trabalhador no } \\
\text { período } t\end{array}$ & $\begin{array}{c}\text { Instituto Brasileiro de } \\
\text { Geografia e Estatística } \\
\text { (IBGE). }\end{array}$ \\
\hline Credt & + & + & $\begin{array}{l}\text { Crédito disponível para pessoas } \\
\text { físicas no período } t\end{array}$ & Banco Central do Brasil \\
\hline$I P I_{t} T_{t}$ & + & + & $\begin{array}{c}\text { Termo de interação da variável } \\
\text { qualitativa e da tendência temporal }\end{array}$ & - \\
\hline Cons & & & & - \\
\hline
\end{tabular}

Fonte: Elaborado pelos autores.

\section{Análise dos Dados}

\subsection{Análise Descritiva}

De acordo com a Tabela 3, foi observado que no ano de 2012 a arrecadação do IPI total representou um montante de $\mathrm{R} \$ 45.927$ milhões, isso correspondeu a uma parcela de $6,66 \%$ da receita com arrecadação de impostos e contribuições e 4,46\% da arrecadação total. 
Já o IPI referente à produção de automóveis representa aproximadamente $9 \%$ da arrecadação do IPI total, mas da arrecadação dos tributos e das receitas totais representa uma parcela muito pequena, que não chega a ser de $1 \%$.

Tabela 3 - Arrecadação das receitas federais 2012 - (R\$ em milhões de 2012)

\begin{tabular}{c|c|c|c}
\hline $\begin{array}{c}\text { Arrecadação } \\
\text { total }\end{array}$ & $\begin{array}{c}\text { Arrecadação de impostos e } \\
\text { contribuições }\end{array}$ & $\begin{array}{c}\text { Arrecadação IPI } \\
\text { total }\end{array}$ & $\begin{array}{c}\text { Arrecadação IPI } \\
\text { automóveis }\end{array}$ \\
\hline 1.029 .259 & 689.768 & 45.927 & 4.126 \\
\hline
\end{tabular}

Fonte: Elaborado pelos autores com base em Receita Federal (2013).

Com a Tabela 4, é perceptível a redução da arrecadação do IPI automóveis no ano de 2009, em decorrência da desoneração do imposto. A participação do IPI automóveis na arrecadação do IPI total caiu para menos da metade em comparação aos três anos anteriores. O mesmo aconteceu em 2012, ano em que ocorreu a redução do IPI automóveis pela segunda vez e a arrecadação também foi menor do que a dos anos anteriores.

Tabela 4 - Arrecadação de IPI total e IPI automóveis (RS em milhões de 2013)

\begin{tabular}{c|c|c|c}
\hline Ano & $\begin{array}{c}\text { Arrecadação de } \\
\text { IPI }\end{array}$ & $\begin{array}{c}\text { Arrecadação de IPI } \\
\text { automóveis }\end{array}$ & $\begin{array}{c}\text { Participação do IPI automóveis na } \\
\text { arrecadação do IPI total }\end{array}$ \\
\hline 2006 & $40.628,6$ & $6.191,5$ & $15,24 \%$ \\
2007 & $47.008,7$ & $7.241,7$ & $15,41 \%$ \\
2008 & $51.975,7$ & $7.906,0$ & $15,21 \%$ \\
2009 & $38.600,4$ & $2.567,4$ & $6,65 \%$ \\
2010 & $47.767,4$ & $6.763,9$ & $14,16 \%$ \\
2011 & $52.610,5$ & $7.834,4$ & $14,89 \%$ \\
2012 & $48.906,2$ & $4.409,0$ & $9,92 \%$ \\
\hline
\end{tabular}

Fonte: Elaborado pelos autores com base em Receita Federal (2013).

A Figura 1 ilustra a venda de automóveis ao consumidor final no período de 2006 até agosto de 2013, conforme dados obtidos junto a Fenabrave (2013). Pode-se perceber que as vendas aumentaram de 2006 até agosto de 2013, mas houve vários momentos em que as vendas diminuíram muito e outros em que cresceram consideravelmente. Ao final do ano de 2008 houve uma drástica redução na compra de veículos e para conter a queda o governo reduziu o IPI. Com a redução, em janeiro de 2009, as vendas começaram a subir novamente.

Figura 1 - Vendas de veículos no varejo

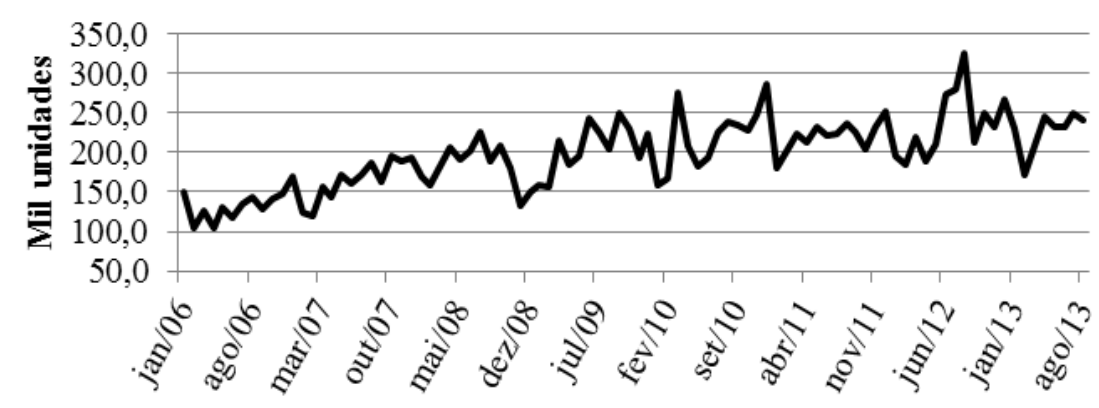

Fonte: Elaborado pelos autores com base em Fenabrave (2013).

A primeira desoneração do imposto terminou no início de 2010 e com isso as vendas caíram novamente. Em maio de 2012 o governo reduziu pela segunda a alíquota do IPI e com 
isso, pode-se observar na Figura 1, que as vendas nesse ano subiram. Contudo, para os dados até agosto, não é possível evidenciar uma tendência de crescimento para 2013.

A Figura 2 mostra que a renda média das pessoas ocupadas vem tendo uma queda considerável de 2006 até o quarto trimestre de 2013, segundo dados do Instituto Brasileiro de Geografia e Estatística (IBGE, 2013). Em janeiro de 2006 a média salarial do trabalhador era de $\mathrm{R} \$ 2.148,9$ e em agosto de 2013 essa média foi de $\mathrm{R} \$ 1.883,0$. Foi uma diminuição de $\mathrm{R} \$$ 265,9, que em termos percentuais corresponde a $12,37 \%$ de queda em relação a janeiro de 2006.

Figura 2 - Renda média das pessoas ocupadas

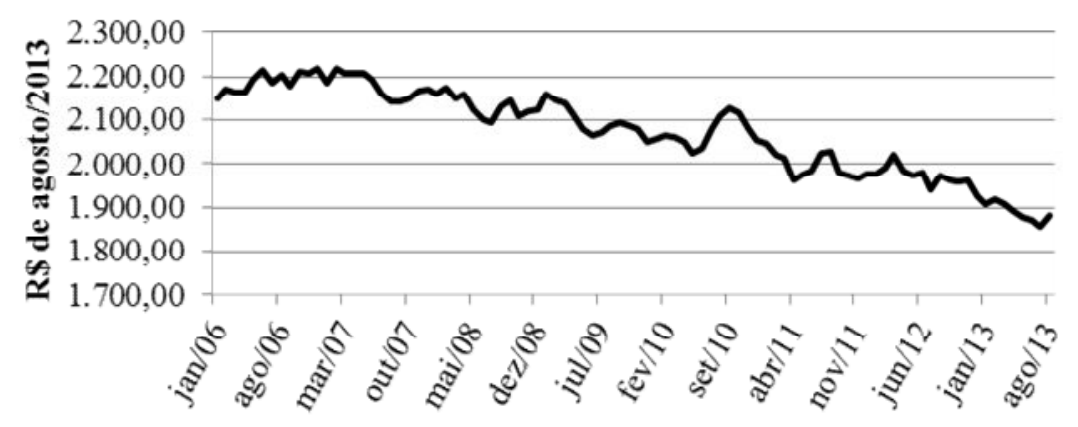

Fonte: Elaborado pelos autores com base em IBGE (2013).

Outro fato importante a ser analisado é o crédito. A disponibilidade de crédito no país altera hábitos de consumo, permitindo a ampliação do consumo e investimento. Pode-se ver a expansão do crédito às pessoas físicas na Figura 3, conforme dados obtidos no Banco Central do Brasil (BCB, 2013).

Figura 3 - Saldo das operações de crédito para pessoas físicas

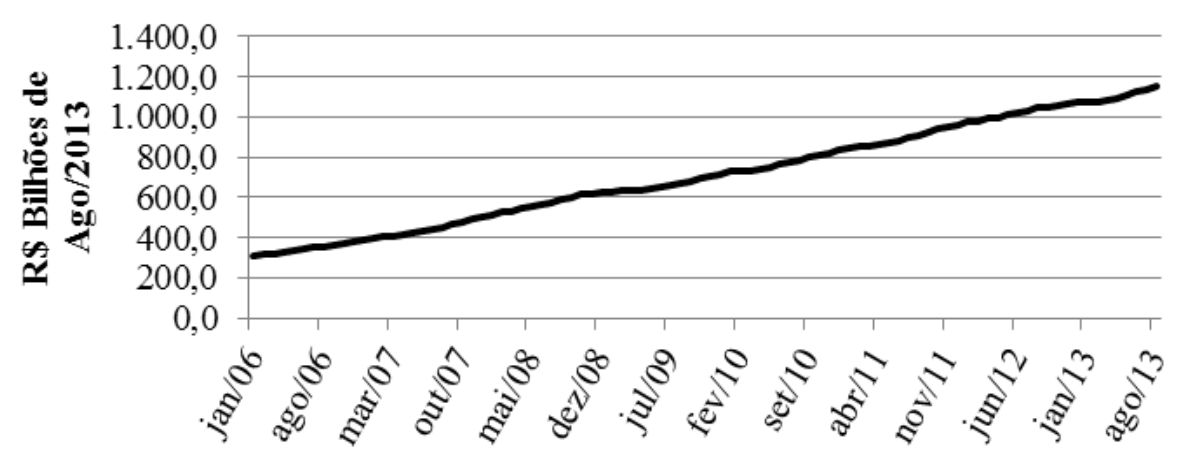

Fonte: Elaborado pelos autores com base em Banco Central (2013).

Em janeiro de 2006 o saldo das operações de crédito para pessoas físicas era de 311,7 bilhões de reais, saldo que aumentou em $269 \%$ até agosto de 2013 , atingindo R $\$ 1,2$ trilhão, a preços de agosto de 2013. Com o aumento da oferta de crédito a população tem a possibilidade de comprar produtos mais caros com prazos mais longos, o que é uma condição importante para o setor automobilístico.

A Figura 4 apresenta a evolução do Índice Gol (IG), preço médio do carro popular, e do Índice Nacional de Preço ao Consumidor Amplo (IPCA). Ambos os índices foram transformados para que a base fosse no mês de janeiro de 2006. Pode-se observar, desse 
modo, que a variação do IPCA no período foi muito maior do que a variação IG. A variação percentual do IG de janeiro de 2006 a agosto de 2013 foi de $7,6 \%$ e a do IPCA foi de $46,1 \%$.

Figura 4 - Relação do índice Gol com o IPCA

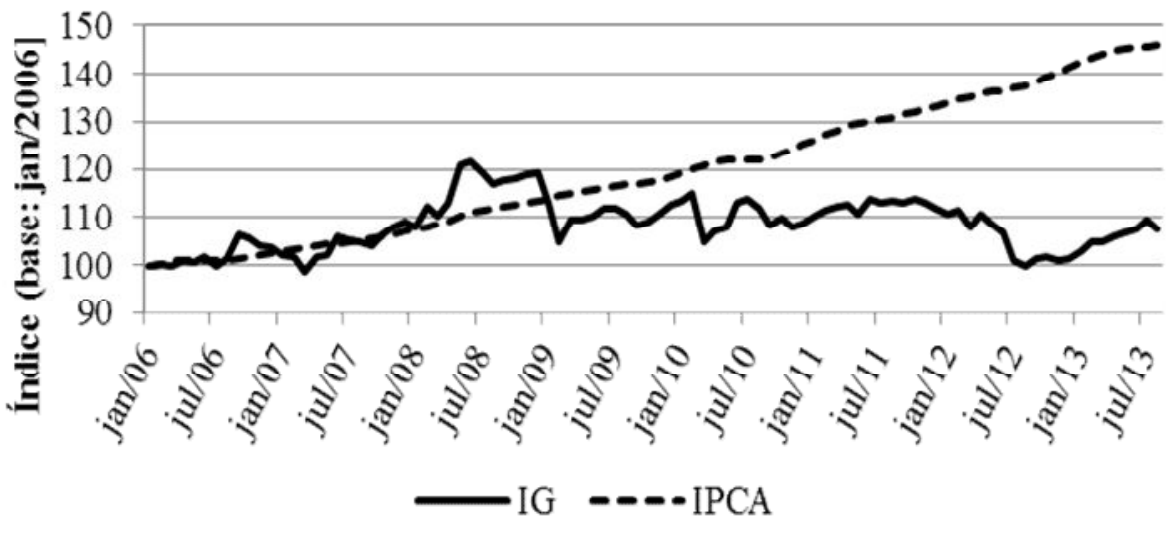

Fonte: Elaborado pelos autores com base em FIPE (2013) e IBGE (2013).

É possível observar na figura que o preço dos veículos teve uma elevação no ano de 2008, que havia iniciado no final de 2007, mas que começou a cair em dezembro de 2008, quando ocorreu a primeira redução do IPI. Depois dessa primeira redução os preços subiram um pouco, mas nada comparado ao que tinha acontecido antes dela. Já no início de 2012 os preços caíram bastante e foi nesse período em que ocorreu a segunda redução do IPI.

A partir do comportamento observado para o IPCA e para o índice do automóvel popular, IG, entende-se que no período estudado ocorreu uma alteração dos preços relativos. Isto é, que os automóveis populares ficaram relativamente mais baratos que os outros bens avaliados pelo IPCA.

\subsection{Análise de Regressão}

Foram realizadas duas regressões, para os dois períodos de redução do IPI. Uma regressão foi no período de janeiro de 2006 até março de 2010 (mês em que acabou a primeira redução) e a outra foi feita para o período de abril de 2010 até agosto de 2013.

Pelo teste de estacionaridade realizado, o teste de Dickey-Fuller Aumentado (Augmented Dickey-Fuller - ADF), conclui-se que a variável venda de automóveis é estacionária para o modelo com intercepto e variável de tendência (Tabelas 7 e 8 no Anexo).

$\mathrm{Na}$ Tabela 3 a seguir, apresentam-se os resultados da regressão para o primeiro período de redução da alíquota do IPI. O Teste $\mathrm{F}$ indica que a regressão como um todo possui significância estatística, isto é, de que é viável o modelo que relaciona a variável dependente venda de automóveis com as variáveis explicativas dummy IPI, tendência temporal, renda e crédito.

$\mathrm{O}$ valor do coeficiente de determinação ( $\mathrm{R}^{2}$-ajustado) indica que as variáveis independentes utilizadas explicam $63,73 \%$ da variação da venda de automóveis. Os valores apresentados da estatística-t indicam não haver relação significativa das variáveis IPI e IPI*T com a venda de automóveis nesse período. Isto é, que a redução da alíquota do IPI não tem relação estatisticamente significante com a venda de automóveis. 
Já com relação às outras variáveis, tendência $(\mathrm{T})$, renda média do trabalhador assalariado (Rend), crédito disponível para pessoas físicas (Cred), foi encontrada uma relação de significância. Chama atenção o fato de tanto a renda como o crédito apresentarem coeficientes negativos, indicando uma relação inversa com a venda de automóveis. Por outro lado, a variável tendência indica relação positiva com as vendas de automóveis.

O resultado obtido com essa primeira regressão conclui, portanto, que a primeira redução do IPI não tem relação com a venda de automóveis.

Tabela 5 - Resultados da Regressão 1 (janeiro de 2006 até março de 2010)

\begin{tabular}{lcc|c|c}
\hline \multicolumn{1}{l}{ Variável Dependente: Venda de automóveis (VA) } \\
\hline \multicolumn{1}{c|}{ Variável } & Coeficiente & Erro Padrão & Estatística-t & Valor p \\
\hline Intercepto (C) & 1337463 & 399953,6 & $3,3^{\mathrm{a}}$ & 0,0017 \\
Redução do IPI (IPI) & 33637,1 & 63333,8 & $0,5^{\mathrm{d}}$ & 0,5980 \\
Tendência (T) & 14007,1 & 3510,4 & $4,0^{\mathrm{a}}$ & 0,0002 \\
Redução do IPI vs. Tendência (IPI*T) & $-1790,9$ & 1566,6 & $-1,1^{\mathrm{c}}$ & 0,2590 \\
Renda média do trabalhador assalariado (Rend) & $-381,8$ & 153,3 & $-2,5^{\mathrm{b}}$ & 0,0165 \\
Crédito disponível para pessoas físicas (Cred) & $-1,3$ & 0,4 & $-3,4^{\mathrm{a}}$ & 0,0013 \\
\hline
\end{tabular}

Número de observações $=51$

$\mathrm{R}^{2}$-ajustado $=0,6373$

Estatística $\mathrm{F}=18,6$ (prob. $=0,0$ )

a:Variáveis com relação estatística forte;

Observações: $\quad$ b:Variável com relação estatística razoável;

c:Variáveis com baixa relação estatística significante;

$\mathrm{d}$ :Variáveis com muito baixa relação estatística significante.

Fonte: Elaborado pelos autores.

$\mathrm{Na}$ Tabela 6, apresentam-se os resultados da regressão para o segundo período de redução da alíquota do IPI. Para a regressão do segundo período, pode-se perceber que o $\mathrm{R}^{2}$ ajustado diminuiu, passando de $63,73 \%$ para $28,20 \%$. Indicando que as variáveis escolhidas diminuíram seu poder explicativo em relação à venda de automóveis. Isso pode indicar que há outros fatores relacionados à venda de carros, que não foram considerados nesta equação. Mesmo assim, o Teste F indica mais uma vez, a significância estatística do modelo como um todo.

Tabela 6 - Resultados da Regressão 2 (abril de 2010 até agosto de 2013)

\begin{tabular}{l|c|c|c|c}
\hline \multicolumn{1}{c}{ Variável Dependente: Venda de automóveis (VA) } \\
\hline \multicolumn{1}{c|}{ Variável } & Coeficiente & Erro Padrão & Estatística-t & Valor p \\
\hline Intercepto (C) & -1078844 & 554856,9 & $-1,9^{\mathrm{c}}$ & 0,0599 \\
Redução do IPI (IPI) & $-17616,6$ & 68921,71 & $-0,3^{\mathrm{d}}$ & 0,7998 \\
Tendência (T) & $-17604,5$ & 8601,7 & $-2,0^{\mathrm{b}}$ & 0,0483 \\
Redução do IPI vs. Tendência (IPI*T) & 2268,1 & 2427,1 & $0,9^{\mathrm{d}}$ & 0,3565 \\
Renda média do trabalhador assalariado (Rend) & 56,91 & 165,7 & $0,3^{\mathrm{d}}$ & 0,7332 \\
Crédito disponível para pessoas físicas (Cred) & 1,61 & 0,8 & $2,1^{\mathrm{b}}$ & 0,0410 \\
\hline
\end{tabular}

Número de observações $=41$

$\mathrm{R}^{2}$-ajustado $=0,2820$

Estatística $\mathrm{F}=2,7$ (prob. $=0,0338)$

a:Variáveis com relação estatística forte;

Observações: $\quad$ b:Variável com relação estatística razoável;

c:Variáveis com baixa relação estatística significante;

d:Variáveis com muito baixa relação estatística significante.

Fonte: Elaborado pelos autores. 
A relação das variáveis, de acordo com o a estatística-t, do segundo momento da redução do IPI foram quase às mesmas da do primeiro momento, com exceção da Renda que apresentou uma relação de significância muito baixa. As variáveis IPI e IPI*Tendência, pela estatística-t, não influenciaram na venda de automóveis. Desta forma, o resultado da segunda regressão também sugere não ter existido relação entre a venda de automóveis e a redução do IPI.

As variáveis Tendência e o Crédito continuam possuindo relação de significância. Neste segundo período o crédito tem relação positiva com as vendas de automóveis, enquanto que a variável tendência impacta negativamente.

Os resultados aqui obtidos são contrários aos obtidos por Alvarenga et al. (2010), conforme comentado anteriormente. Neste trabalho não foi encontrada relação de significância entre a redução do imposto e as vendas. Alguns dos fatores que podem ter influenciado nessa divergência de resultados são as variáveis escolhidas ou teste realizado. Outra consideração é de que a redução da alíquota pode não ter aumentado as vendas de automóveis, mas talvez o efeito tenha sido na verdade de evitar que as vendas caíssem.

\section{Considerações Finais}

Este trabalho teve como objetivo verificar se a redução da alíquota do IPI automóveis gerou alterações sobre as vendas de veículos no varejo. Foram utilizados dados mensais para o período de janeiro de 2006 a agosto de 2013. Desta forma, a partir da análise de estatística descritiva foi possível observar que o IPI dos automóveis na época em que ocorreram as reduções passou a representar uma parte menor do IPI total. No ano de 2009, por exemplo, a parcela do IPI automóveis que representava o IPI total caiu para menos da metade se comparado com os anos seguintes.

Em termos gerais, as vendas dos veículos apresentaram crescimento e grande oscilação. $\mathrm{O}$ crédito destinado às pessoas físicas teve um grande aumento no período, mas em contrapartida a renda média das pessoas ocupadas sofreu redução real.

Com a realização dos testes de regressão, os resultados obtidos não mostraram relação de significância entre a redução do IPI e a venda de automóveis, para nenhum dos dois períodos analisados. Assim, não é possível afirmar que a venda de automóveis foi alterada pela redução do imposto.

As variáveis renda e crédito apresentaram relação de significância na primeira análise, portanto contribuíram para que as vendas aumentassem. Na segunda análise o crédito continuou tendo uma relação estatística razoável, mas a renda passou a ter uma baixa relação estatística significante. Esta redução do poder explicativo da renda pode estar relacionado com a redução real da renda do trabalhador.

Pondera-se, porém, que a redução das alíquotas do IPI pode não ter causado uma alteração da tendência das vendas de automóveis. Por outro lado, pode ser que sem essa redução das alíquotas, o resultado teria sido uma redução das vendas.

Conclui-se assim, que o tema pesquisado merece maiores investigações, podendo tanto ter a aplicação de outros testes quanto à utilização de novas variáveis que possam interferir positivamente na venda de veículos no Brasil e exterior. Logo, é de grande importância que as políticas de incentivo do Governo Federal sejam estudadas e avaliadas, já que usualmente representam desembolso de recursos ou a renúncia destes. 


\section{Referências}

ALVARENGA, G.V.; ALVES, P. F.; DOS SANTOS, C. F.; DE NIGRI, F.; CAVALCANTE, L. R.; PASSOS, M. C. Políticas anticíclicas na indústria automobilística: uma análise de cointegração dos impactos da redução do IPI sobre as vendas de veículos. Brasília, DF: IPEA, 2010. 36 p. (Texto para discussão, n. 1512).

BANCO CENTRAL DO BRASIL. Saldo das Operações de Crédito do Sistema Financeiro Nacional - Pessoas Físicas. Disponível em:

https://www3.bcb.gov.br/sgspub/localizarseries/localizarSeries.do?method=prepararTelaLoca lizarSeries. Acesso em: novembro/2013.

BRASIL. Código Tributário Brasileiro. Dispõe sobre o Sistema Tributário Nacional e institui normas gerais de direito tributário aplicáveis à União, Estados e Municípios. Disponível em: http://www.planalto.gov.br/ccivil_03/leis/15172.htm. Acesso em: novembro/2013

BRASIL. Constituição da República Federativa do Brasil de 1988. Disponível em: http://www.planalto.gov.br/ccivil_03/constituicao/constituicaocompilado.htm. Acesso em: novembro/2013.

BRASIL. Decreto $n^{0}$ 4.544/2002. Regulamenta a tributação, fiscalização, arrecadação e administração do Imposto sobre Produtos Industrializados - IPI. Disponível em: http://www.receita.fazenda.gov.br/Legislacao/Decretos/2002/dec4544.htm. Acesso em: setembro/2013

BRASIL. Decreto no 7212/2010. Regulamenta a cobrança, fiscalização, arrecadação e administração do Imposto sobre Produtos Industrializados - IPI. Disponível em:

http://www.planalto.gov.br/ccivil_03/_Ato2007-2010/2010/Decreto/D7212.htm. Acesso em: setembro/2013

BRASIL. Decreto $\mathbf{n}^{\mathbf{0}} \mathbf{7 6 6 0 / 2 0 1 1}$. Aprova a Tabela de Incidência do Imposto sobre Produtos Industrializados - TIPI. Disponível em:

http://www.receita.fazenda.gov.br/Legislacao/Decretos/2011/dec7660.htm. Acesso em: outubro/2013

BRASIL. Decreto $\mathbf{n}^{\mathbf{0}} \mathbf{8 1 1 6 / 2 0 1 3}$. Altera a Tabela de Incidência do Imposto sobre Produtos Industrializados - TIPI, aprovada pelo Decreto no 7.660, de 23 de dezembro de 2011. Disponível em:

http://www.receita.fazenda.gov.br/Legislacao/Decretos/2013/dec8116.htm. Acesso em: outubro/2013

BRASIL, Emenda Constitucional no 18 de 1965. Reforma do Sistema Tributário. Disponível em: 
http://legis.senado.gov.br/legislacao/ListaPublicacoes.action?id=116129. Acesso em: novembro/2013

BRASIL, Medida Provisória n⿳ 451/2008. Altera a legislação tributária federal, e dá outras providências. Disponível em:

http://www.receita.fazenda.gov.br/Legislacao/MPs/2008/mp451.htm. Acesso em: setembro/2013

CASOTTI, B. P.; GOLDENSTEIN, Marcelo. Panorama do setor automotivo: as mudanças estruturais da indústria e as perspectivas para o Brasil. BNDES Setorial, Rio de Janeiro, n. 28 , p.147-188, set. 2008

\section{FEDERAÇÃO NACIONAL DA DISTRIBUIÇÃO DE VEÍCULOS AUTOMOTORES} (Fenabrave). Dados referentes à venda no varejo de veículos automotores. Disponível em: http://www3.fenabrave.org.br:8082/plus/modulos/conteudo/?tac=varejo-nacional. Acesso em: outubro/2013.

\section{FEDERAÇÃO NACIONAL DA DISTRIBUIÇÃO DE VEÍCULOS AUTOMOTORES} (Fenabrave). Dados referentes ao ranking dos grupos de modelos de veículos novos mais vendidos. Disponível em: http://www3.fenabrave.org.br. Acesso em: outubro/2013.

FERREIRA, Aurélio Buarque de Holanda. Novo Dicionário Eletrônico Aurélio versão 6.0. Editora Positivo, 2009.

FUNDAÇÃO INSTITUTO DE PESQUISA ECONÔMICAS (Fipe). Dados referentes ao preço médio de veículos. Disponível em: http://www.fipe.org.br/web/index.asp. Acesso em: novembro/2013.

FRANZOI, Fabrisia. O impacto da redução do IPI dos veículos automotores, em virtude da crise financeira. Revista Direito UNIDAVI, Rio do Sul, N.2, Junho 2012. Disponível em: http://www.revistadireito.unidavi.edu.br/. Acesso em: agosto/2013

FREITAS, Maria C. P. de. Os efeitos da crise global no Brasil: aversão ao risco e preferência pela liquidez no mercado de crédito. Estudos Avançados, São Paulo, 23 (66), p.125-145, 2009.

GUJARATI, Damodar .N. Econometria Básica. 3. ed. São Paulo: Makron Books, 2000.

INSTITUTO BRASILEIRO DE GEOGRAFIA E ESTATÍSTICA (IBGE). Dados referentes à renda média do trabalhador ocupado. Disponível em:

http://www.ibge.gov.br/home/estatistica/indicadores/trabalhoerendimento/pme_nova/defaultta b hist.shtm. Acesso em: novembro/2013

INSTITUTO DE PESQUISA ECONÔMICA APLICADA (IPEA). Dados referentes ao Índice Nacional de Preços ao Consumidor Amplo (IPCA). Disponível em: http://www.ipeadata.gov.br/. Acesso em: novembro/2013 
MANTEGA, Guido. Apresentação do ministro da Fazenda, Guido Mantega no Senado Federal. Ministério da Fazenda, Brasília, 21 maio 2012. Disponível em:

https://www.fazenda.gov.br/divulgacao/noticias/2012/maio/mantega-explica-no-senadomudanca-na-remuneracao-da-caderneta-de-poupanca. Acesso em: outubro/2013.

RECEITA FEDERAL DO BRASIL. Dados referentes à arrecadação do IPI total e automóveis e a arrecadação de tributos e receitas. Disponível em:

http://www.receita.fazenda.gov.br/Historico/Arrecadacao/ResultadoArrec/default.htm.

Acesso em: novembro/2013.

Scavarda, Luis F. R.; Hamacher, Sílvio. Evolução da Cadeia de Suprimentos da Indústria Evolução da Cadeia de Suprimentos da Indústria Automobilística no Brasil

Automobilística no Brasil. Revista de Administração Contemporânea (RAC), Rio de Janeiro, v. 5, n. 2, p. 201-219, 2001.

XAVIER, Manoela F. S. IPI: Imposto sobre Produtos Industrializados. Rio de Janeiro: Maria Augusta Delgado, 2008. Disponível em:

http://www.multieditoras.com.br/produto/PDF/600102.pdf. Acesso em: novembro de 2013 
ANEXO A - Teste de Estacionaridade para Regressão

Tabela 7 - Teste de Estacionaridade para Regressão 1 (janeiro de 2006 até março de 2010)

\begin{tabular}{ccc}
\hline Teste & Estatística t & Valor p \\
\hline $\begin{array}{c}\text { Augmented Dickey-Fuller (ADF) } \\
\text { (intercepto e tendência) }\end{array}$ & $-3,9$ & 0,019 \\
\hline
\end{tabular}

Fonte: Elaborado pelos autores.

Tabela 8 - Teste de Estacionaridade para Regressão 2 (abril de 2010 até agosto de 2013).

\begin{tabular}{ccc}
\hline Teste & Estatística t & Valor p \\
\hline $\begin{array}{c}\text { Augmented Dickey-Fuller (ADF) } \\
\text { (intercepto e tendência) }\end{array}$ & $-4,7$ & 0,003 \\
\hline
\end{tabular}

Fonte: Elaborado pelos autores. 